\title{
Development a Model for the Evaluation and Improvement of Key Human Resource Competencies Using the Grounded Theory
}

\author{
Homayoun Nouri $^{1} \oplus$, Nour Mohammad Yaghoubi ${ }^{2} \oplus$, Ebrahim Haddadi $^{3} \oplus$, \\ Said Mehdi Viseh ${ }^{4}$
}

Date of submission: 28 Sep. 2019

Date of acceptance: 22 Dec. 2020

\section{Original Article}

\begin{abstract}
INTRODUCTION: The Red Crescent Society of the Islamic Republic of Iran is a human-centered organization. Therefore, the competencies of its employees must be improved to make it possible for them to have their best performances. In this regard, the present study aimed to investigate and identify the factors that affect the development of key human resource competencies in the Iranian Red Crescent Society and design an appropriate model for its evaluation.
\end{abstract}

METHODS: The present applied qualitative research used an exploratory approach. The statistical population of this study consisted of managers and experts in the field of human resources of the Red Crescent Society who were selected using the snowball sampling method. Moreover, the required data were collected through semi-structured in-depth interviews and we reached saturation after 26 interviews. The collected data were analyzed using the Straussian version of grounded theory. Finally, the collected data were analyzed in the MAXQDA software (version 10). In total, 72 concepts, 568 sub-concepts, and 19 categories were identified in this research.

FINDINGS: Five out of the seven fundamental principles of the Red Crescent Society and the International Committee of the Red Cross, including the principle of humanity, voluntary service, neutrality, impartiality, and independence are among the foundational factors and necessities of the development of human resources competencies and were axially coded in causal conditions. Improvement and development of individual, organizational, social, and professional competencies were the four main categories of this research that were selected as the main strategies for the development of human resource competencies.

CONCLUSION: According to the results of data analysis, employing appropriate strategies for the evaluation and development of key human resources competencies can have beneficial consequences. More specifically, these categories include human resource efficiency, provision of desirable social services, enhancement of the community health, improvement of human values, increase of public trust and participation, and improvement of the financial position of the organization.

Keywords: Competence; Grounded Theory; Human Resource Development; Red Crescent Society.

How to cite this article: Nouri H, Yaghoubi NM, Haddadi E, Viseh SM. Development a Model for the Evaluation and Improvement of Key Human Resource Competencies Using the Grounded Theory. Sci J Rescue Relief 2020; 12(1): 13-22.

1-PhD Student, Department of Public Administration, Faculty of Literature \& Humanities, Islamic Azad University, Zahedan Branch, Zahedan, Iran

2-PhD, Department of Public Administration, Faculty of Management and Economics, University of Sistan and Baluchestan, Zahedan, Iran

3-PhD, Department of Public Administration, Faculty of Literature and Humanities, Islamic Azad University, Zahedan Branch, Zahedan, Iran

4-PhD, Department of Public Administration, Faculty of Literature and Humanities, Ilam University, Ilam, Iran

Correspondence to: Nour Mohammad Yaghoubi, Email: yaghoubi@mgmt.usb.ac.ir 


\section{Introduction}

$\mathrm{H}$ uman resource management is defined as a system for the proper use of human resources to achieve the predetermined goals of an organization. In today's competitive environment, human resource is one of the main assets of any organization whose contribution to its success is undeniable (1). As a result, it seems necessary to equip this unique asset with information, knowledge, and skills in order to maximize job performance (2). Undoubtedly, the training and development system, as one of the main methods of competency development, plays a strategic role in this regard (3).

Competency is a criterion that is commonly used for the evaluation of human resources in various organizations which makes it possible to evaluate and develop the capabilities of the employees that are important to the organization (4). Therefore, it can be said that the development of competencies and their functions can help the organization in the face of a changing environment (5).

Lepaite (2003) declared that the successful activities of employees in global organizations depend on their ability to adapt to changing environments, in which competence and development potential have become key factors (6).

Therefore, it is very important to choose the right model for competency assessment. Competency is based on individual competencies or levels of competency and accumulated professional experience. This means that employees should be equipped with specific functional abilities, i.e. professional competencies for the proper performance of their jobs. Therefore, for instance, the warehouse operations manager must have the skill and ability in this field of profession. Hence, besides paying attention to personnel or human resources and focusing on the appropriate current requirements regarding individual competencies, it is also important to anticipate the competencies that determine future success.

According to the available perspectives on professional competency, it can be said that the general abilities, as well as professional and scientific competencies, depend on the developed profession. In other words, competencies are interdependent and contextual (6).

Therefore, due to the importance of the discourse of human resources and competence, special attention should be paid to this issue in organizations. The Red Crescent Society, as an Iranian organization, is no exception to this rule, however, this relief and non-profit organization has not done anything regarding the development of human resource competencies so far. Majority of the activities of this society focus on the issue of first-aid preparation and education and its slogan is "family preparedness for disasters". Moreover, many of its programs concentrate on public relief education.

On the other hand, the Red Crescent Society, as the search and rescue organization of the country, has a heavy responsibility regarding the disaster victims. This matter has gained even more importance due to the expansion of science and industry, rapid technological advancement, and the growth of the world population (7). Therefore, in the Iranian Red Crescent Society, as an organization that plays an important role in the provision of assistance to members of the society, the competencies of the employees should be promoted to make it possible for them to have their best performances.

The current situation of the Red Crescent Society indicates the lack of a comprehensive model for the assessment and development of human resource competencies. The Red Crescent Society is a human-centered organization, meaning that most of the services it provides to its target communities are based on the services provided by the human resources of the organization. Therefore, the lack of a model for the evaluation and development of the competencies of these valuable resources has significant consequences that affect all aspects of the organization.

The managers of this organization are not satisfied with this situation. The evaluation of managers and employees based on the criteria other than competency causes dissatisfaction in the whole organization and reduces work efficiency. In addition, it can cause several other problems for the organization, such as difficulty in finding substitutes.

Given the importance of the evaluation and development of competencies in the Red Crescent Society of the Islamic Republic of Iran and the existing gap in this regard, the researchers decided to reduce this gap by the conduction of the present research. In this regard, this study aimed to investigate and evaluate the key competencies of human resources in the Iranian Red Crescent 
Society and provide an appropriate model for this evaluation.

\section{Methods}

The present applied qualitative research used an exploratory approach and the collected data were analyzed based on the Straussian version of the grounded theory. The required data were mainly collected through semi-structured in-depth interviews, while the questions were open-ended and general. We reached saturation after 26 interviews with managers and experts in the field of human resource development of the Red Crescent Society as well as experts and university professors in the field of management.

The subjects were selected using the purposive snowball sampling method. Moreover, the research data were analyzed using the grounded theory; accordingly, the interview and textual data were coded through three stages, namely open, axial, and selective coding. First, the initial codes were extracted from the interviews (coding of key points). Subsequently, in the open coding stage, the codes that referred to a similar subject were grouped and formed concepts which, in turn, were divided into categories.

In total, 72 concepts, 568 sub-concepts, and 19 categories were identified and organized in MAXQDA software (version 10). In the axial coding stage, in order to link the main categories to the subcategories, the coding paradigm model was used to determine the causal conditions, central phenomena, context, intervening conditions, strategies, and outcome that are the components of the axial coding. Subsequently, through selective coding and based on the identified relationship pattern between categories and subcategories in open and axial coding, the categories were connected to each other and the relevant system was presented. (Table 1)

\section{Findings}

\section{Demographic characteristics}

According to obtained data from the demographic characteristics form, 9 (35\%) participants were female and $17(65 \%)$ were male. Moreover, 4 (15\%), $11(42 \%), 9$ (36\%), and 2 (7.6\%) participants were under 30 years old, 3040 years old, 40-50 years old, and 50 years old and above. In terms of work experience, 3 (11.5\%), $11(42 \%), 10(38.5 \%)$, and $2(7.6 \%)$ subjects had less than 5 years, 5-15 years, 15-25 years, and more than 25 years of work experience.

Description of the variables of the key human resource competencies in the Red Crescent Society

In order to obtain the required data to meet the objectives of the research, in-depth and semistructured interviews were conducted with professors, managers, and experts in the field of management, and each interview was analyzed immediately. In the theory analysis process, the interview and textual data were coded in three phases, namely open, axial, and selective coding. Each of these steps is described below.

Open coding is performed in two stages of primary and secondary coding. Primary coding can be done by attaching a concept or code to each line, phrase, or paragraph. In secondary coding, the extracted concepts were compared and similar concepts were placed in the same categories. Therefore, the collected data (codesconcepts) was reduced to a certain and limited number of main categories.

\section{Open coding}

In open coding, the researchers extracted specific concepts and codes by reviewing and studying the conducted interviews verbatim. For

Table 1. Layers of the present research

$\begin{array}{cc}\text { Layers of the research } & \text { Characteristics of the research } \\ \text { Research orientation } & \text { Basic-descriptive-applied } \\ \text { Research methods } & \text { Qualitative } \\ \text { Research philosophy } & \text { Interpretive } \\ \text { Research approach } & \text { Inductive } \\ \text { Research strategy } & \text { Grounded theory (inferential and structural equation) } \\ \text { Research purpose } & \text { Exploratory-confirmatory } \\ \text { Research instruments } & \text { Semi-structured interviews, their theoretical foundations, and their analysis; review of the } \\ & \text { documents; and questionnaire }\end{array}$

this purpose, the researchers used MAXQDA software (version 10) which is a qualitative data 
analysis software. In the first stage, 72 different codes or concepts were extracted which had been repeated 568 times in the interviews.

As mentioned earlier, open coding was done in the primary and secondary stages. In the secondary coding, the concepts were compared and similar items were placed in the same category. Therefore, the obtained data (codesconcepts) were reduced to a certain and limited number of main categories that were subsequently connected to each other.

Table 2 summarizes the attempt to place

Table 2. Categorization of the codes

Category

Individual competencies

Communicational and social competencies

Professional competencies

Organizational competencies

Human resource efficiency

Provision of desirable social services

Improvement of the community health

Improvement of humanitarian values

Improvement of the financial position of the organization

Increase of public trust and participation

Humanity principle

Voluntary service principle

Neutrality principle

Impartiality principle

Independence principle

Public culture principle

Senior management support

Laws and regulations

Effective and continuous evaluation and provision of feedback regarding human resource competencies
Related concepts

Responsibility/discipline/values and

attitudes/personality/ethics/promptitude/intelligence and talent/selfconfidence/patience /non-bias

Appropriate workplace relationships/ability to participate and work in a team/ability to actively listen/establishment of emotional communication with fellow human beings/ability to transfer experiences and skills to others/creation of a sense of

friendship and cooperation between people/effective verbal skills

Operational skills/expertise/problem recognition and resolution/crisis management/time management

Organizational commitment/organizational loyalty/organizational knowledge/organizational sense of belonging/organizational culture

Expert human resources/trusted human resources/religious human resources/motivated human resources /loyal human resources

Effective education on prevention and safety activities/effective education on relief activities

Reduction of the pain and sorrows of humans/increase of life expectancy/improvement of the public health indicators/reduction of the casualties due to crises and events

Empathy/peace and friendship/sacrifice and altruism /assistance of others/kindness/preservation of human dignity

Increase of voluntary financial aid/increase of the participation of organizations/allocation of appropriate budget

Increase of voluntary services/increase of members of the organization/increase of trust

The need to protect the life and health of humans / the need to preserve human dignity and values/establishment of lasting cooperation and peaceful relationships among human beings

Lack of attention to profitability/voluntary service/willingness to serve

Impartiality in conflicts/non-participation in religious-political disputes

Lack of political and religious orientation/prioritization based on more critical issues

Maintenance of independence while respecting the laws of the country/lack of formal or informal affiliation with other organizations

Dominant culture of the society/type of public attitude towards the Red Crescent Society activities

Role of the senior management in manpower motivation/logic and the attitude of the management

Organizational laws/laws of government and governing institutions

Effective evaluation/provision of feedback/material incentives/spiritual incentives 
similar and common concepts in a single category and determine the main categories of research. (Table 2)

Based on Table 2, 19 main categories were identified, which will be examined in the next step through the axial coding stage.

\section{Axial coding}

In the axial coding stage, the researchers selected a category from the open coding stage and placed it in the center of the studied process (as the central phenomenon or category) and afterward connects other categories to it. The other categories were "causal conditions", "strategies", "contextual and intervening conditions", and "consequences". This step involved drawing a diagram called the "coding pattern". (Figure 1)

According to the main topic of the interview and the research subject, the central phenomenon of this research was the development of key human resource competencies in the Iranian Red Crescent Society. Among these, causal conditions are the categories that affect the central phenomenon. In this study, five out of the seven principles of the Red Crescent Society and the International Red Cross, including the principles of humanity, voluntary service, neutrality, impartiality, and independence, which comprise the infrastructure and necessities of human resource development, were axially coded in causal conditions. In other words, one of the basic requirements for achieving these five principles is the development of key human resource competencies.

Improvement and development of individual, organizational, social, and professional competencies are the four main categories of this research that have been selected as the main strategies for the development of human resource competencies. In other words, the development of key human resource competencies depends on the development of the individual, social, professional, and organizational competencies.

Public culture, senior management support, and laws and regulations of the country are three intervening categories that affect strategies. Moreover, they influence the effective and continuous evaluation and provision of feedback regarding human resource competencies as a contextual category for the development of human resource competencies.

Outcomes are the output of employing appropriate strategies for the development of key human resource competencies and their continuous and effective evaluation. In this study, the categories of human resource efficiency, provision of desirable social services, improvement of the community health, improvement of human values, increase of public trust and participation, and improvement of the financial position of the organization are the consequences of employing appropriate strategies for the evaluation and development of key human resource competencies. (Table 3)

\section{Selective coding}

"Selective coding" is the process of integrating and improving categories. At this stage of coding, based on the Grounded Theory, the researchers form a theory about the relationships of the categories in the axial coding model. In selective coding, the theory is integrated and refined through techniques, such as storyline writing that

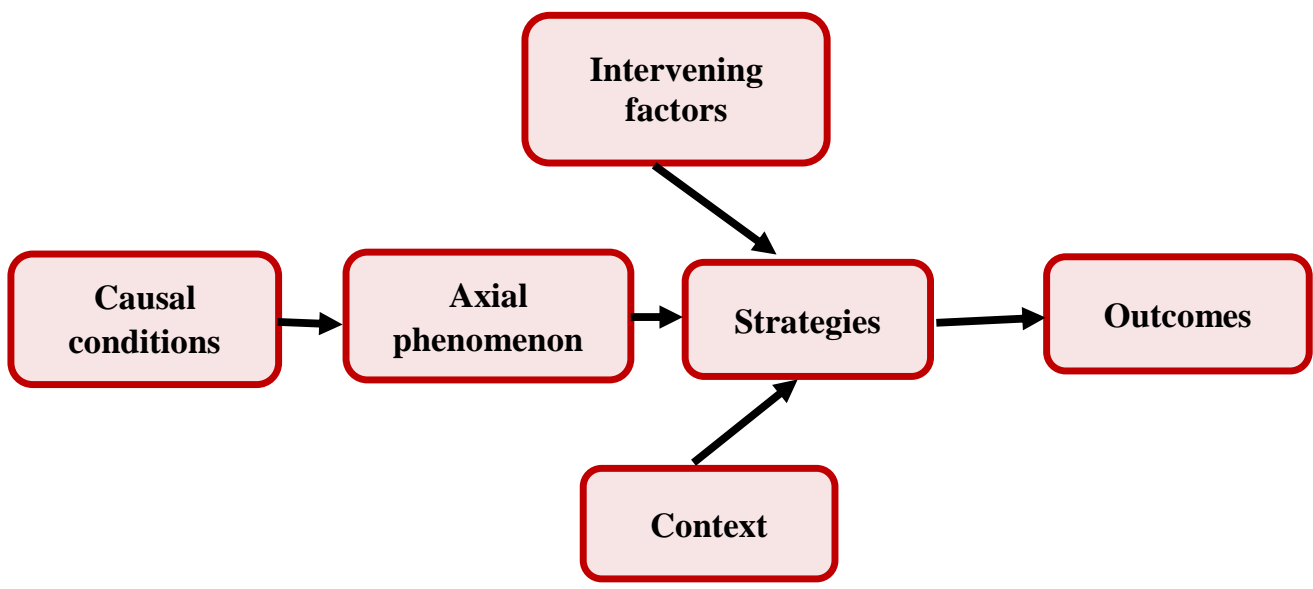

Figure 1. Coding pattern 
connects the categories to each other. In a storyline, the researcher examines how specific factors affect the phenomenon and lead to the use of specific strategies with particular outputs.

Due to the nature of the duties and missions of the Red Crescent Society, one of the important tools to fulfill them is the human element and human resources. Role of humans in the organization and the attitude towards them is of significant importance to the successful completion of missions and crisis management. Due to the non-profit and voluntary nature of the services of the Red Crescent Society, many challenges can face the human resources of this organization if they are ignored.

It can be said that the basic principles of the Red Crescent Society, namely principles of humanity, voluntary service, neutrality, impartiality, and independence, require competent human resources, which can be achieved through the improvement and development of the individual, communicational-social, professional, and organizational compe-tencies in the context of effective evaluation and provision of appropriate feedback. In this way, various factors, such as the public culture, senior management support, and laws of the country can also make the goal achievement easier or more difficult. The Red Crescent Society can achieve its goals only in case of improvement and development of competencies which consist of the efficiency of human resources, provision of desirable social services, improvement of community health, improvement human values, increase of public trust and participation, and improvement of the financial position of the organization. (Figure 2)

Table 3. Descriptive indicators of the studied variables

\begin{tabular}{|c|c|c|c|c|c|}
\hline \multicolumn{2}{|r|}{ Variable } & Mean & SD & Minimum & Maximum \\
\hline \multirow{4}{*}{$\begin{array}{l}\text { Causal } \\
\text { conditions }\end{array}$} & Humanity principle & 3.175 & 1.265 & 1 & 5 \\
\hline & Voluntary services principle & 3.189 & 1.262 & 1 & 5 \\
\hline & Neutrality principle & 3.550 & 1.027 & 1 & 5 \\
\hline & Impartiality principle & 3.579 & 0.976 & 1 & 5 \\
\hline \multirow{5}{*}{$\begin{array}{l}\text { Intervening } \\
\text { factors }\end{array}$} & Independence principle & 3.582 & 1.124 & 1 & 5 \\
\hline & Public culture & 3.304 & 1.177 & 1 & 5 \\
\hline & Senior management support & 3.365 & 1.030 & 1 & 5 \\
\hline & Laws of the country & 3.316 & 1.233 & 1 & 5 \\
\hline & Improvement and development of individual competencies & 3.402 & 1.183 & 1 & 5 \\
\hline \multirow{3}{*}{ Strategies } & Improvement and development of organizational competencies & 3.220 & 1.081 & 1 & 5 \\
\hline & $\begin{array}{l}\text { Improvement and development of communicational-social } \\
\text { competencies }\end{array}$ & 3.146 & 1.081 & 1 & 5 \\
\hline & Improvement and development of professional competencies & 3.230 & 1.278 & 1 & 5 \\
\hline \multirow[t]{2}{*}{ Context } & $\begin{array}{l}\text { Continuous evaluation and provision of feedback regarding } \\
\text { human resource competencies }\end{array}$ & 3.655 & 0.942 & 1 & 5 \\
\hline & Human resource efficiency & 3.676 & 0.872 & 1 & 5 \\
\hline \multirow{5}{*}{ Outcomes } & Provision of desirable social services & 3.735 & 0.948 & 1 & 5 \\
\hline & Improvement of the community health & 3.640 & 0.976 & 1 & 5 \\
\hline & Improvement of human values & 3.652 & 0.983 & 1 & 5 \\
\hline & Increase of public trust and participation & 3.655 & 0.869 & 1 & 5 \\
\hline & improvement of the financial position of the organization & 3.079 & 1.166 & 1 & 5 \\
\hline
\end{tabular}




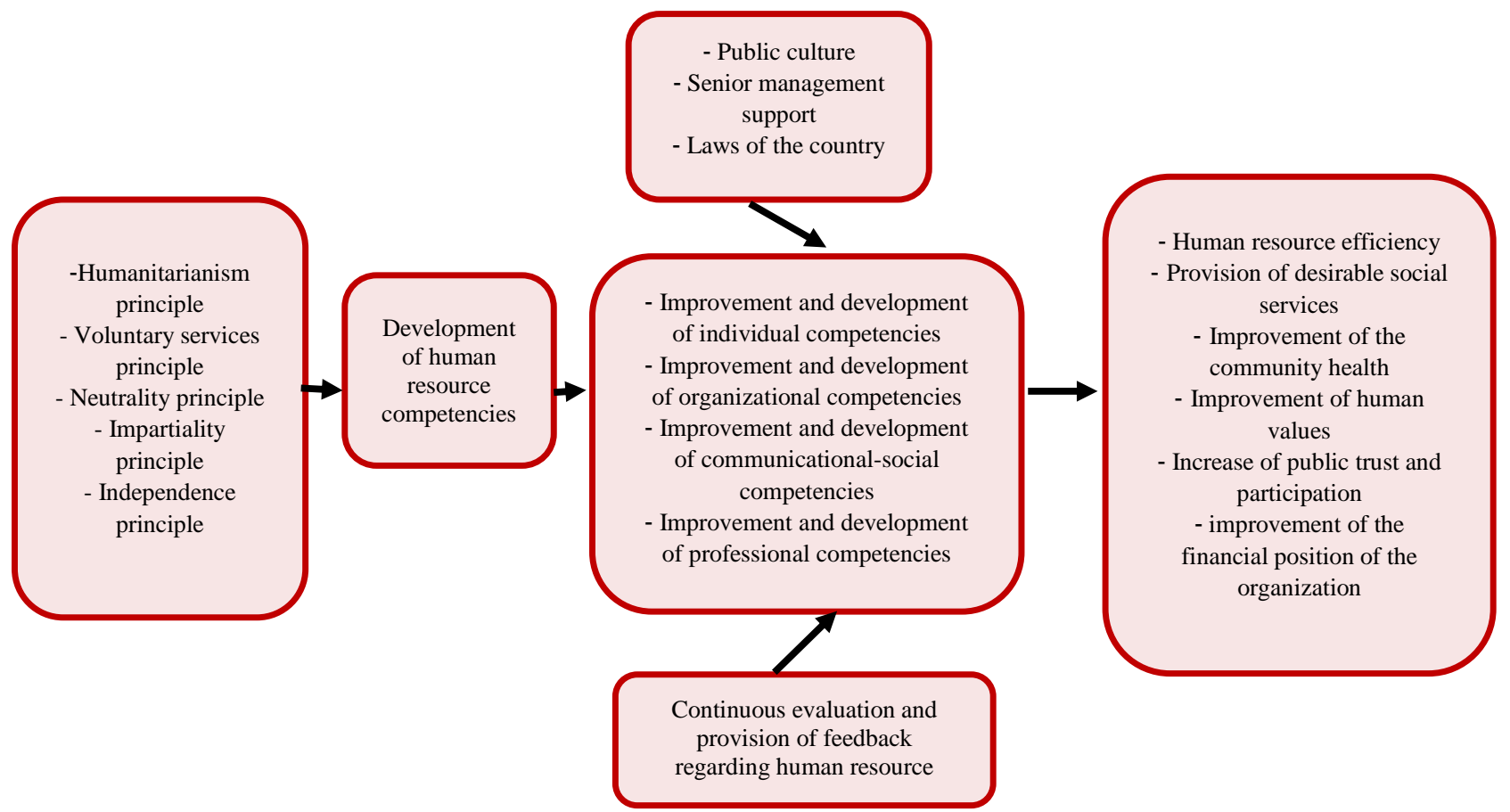

Figure 2. Model of coding the evaluation and development of key human resource competencies in the Iranian Red Crescent Society

\section{Discussion and Conclusion}

Since the mid-1980s, organizations have started to pay attention to the evaluation and development of human resource competencies. The main reason for this attention was the belief that the development of human resource competencies brings innumerable benefits to organizations, and this belief still persists (8). The competency-oriented approach to employees, as a strategic fundamental principle is actually the link between employees and their organization. Moreover, an organization can compete with other organizations around the world in terms of the competencies of their employees (9).

Human resources and its development and empowerment are considered the most valuable organizational assets and the axis of ability and knowledge enhancement at the world level. Therefore, it can be acknowledged that the attention to human resources confirms the fact that human beings are considered as decisive and effective partners of an organization and the development of their competencies leads to the comprehensive and balanced development of the organization. Hence, carrying out value-creating and transformational measures in the field of human resource management provides the possibility of developing core competencies in the work environment (10).
Therefore, due to the importance of human resources and competency, special attention should be paid to this important issue in organizations. The Iranian Red Crescent Society, as a relief and public utility organization, is no exception to this rule. However, no activity has been carried out in this regard in this organization, while the main part of its services is focused on the issue of preparedness and first aid training, their slogan is "family preparedness for disasters", and the majority of its programs are directed towards public relief education.

Moreover, the Red Crescent Society, as the search and rescue organization of the country, has a heavy responsibility regarding the disaster victims. The importance of this issue has increased with the advancement of science and technology, as well as rapid technological progress and population growth (11). Therefore, since the Iranian Red Crescent Society has an important role in the provision of assistance to the members of the society, its human resource competencies should be promoted in order to help them show their best performance.

In this study, five out of the seven principles of the Red Crescent Society and the International Red Cross, including the principles of humanitarianism, voluntary service, neutrality, impartiality, and independence. These principles are the infrastructure and necessities of human 
resource development and were axially coded in causal conditions. In other words, one of the basic requirements for achieving these five principles is the development of key human resource competencies.

Improvement and development of individual, organizational, social, and professional competencies are the four main categories of this research that have been selected as the main strategies for enhancement human resource competencies. In other words, in order to develop the key competencies of human resources, these competencies must be developed and improved in the individual, social, professional, and organizational aspects.

Public culture, senior management support, laws of the country are the intervening categories that influence strategies and impact the effective and continuous evaluation of human resource competencies, as a contextual category for the development of human resource competencies.

Due to the voluntary and non-profit nature of the services provided by the Red Crescent Society, many challenges can face the human resources of the organization if they are neglected. Managers of the organization can resolve these issues or prevent the occurrence of most of them by empowering their employees. Empowered employees cooperate with managers to solve problems since empowering human resources leads to motivation, participation, commitment, and loyalty.

Therefore, if the organization wants to achieve the seven principles, it has to develop its human resource competencies in order to increase their efficiency, help the organization provide better services, increase public trust and participation, and ultimately improve its economic situation. Human resources can adhere to the principles of voluntary service, neutrality, impartiality, independence, and humanity if they receive the necessary training in various fields and become empowered in them.

Human resources should have individual competencies such as responsibility, discipline, ethics and politeness, promptitude, intelligence and talent, self-confidence, patience, and nonbias. Their attitudes and values should be in line with the goals and missions of the organization. They must be willing to help fellow human beings and it must be noted that all of these characteristics can be trained and developed. At the same time, the employees should know that they will be evaluated regarding these characteristics and this evaluation affects their progress and encouragement or even punishment.

In addition to individual competencies, professional competencies must be improved and developed as well, including specialized knowledge, the ability to manage crises in the event of natural and human-made disasters, time management skills, and the ability to make the fast decisions to solve a problem. All of these competencies depend on education and development which must be constantly evaluated. In this regard, the senior management support can also play an intervening role to slow down or accelerate the goal-achievement process.

Another factor that can realize the requirements of the principles of humanity and voluntary service is the improvement and development of communication and social competencies. At the first level, it means that the employees should be able to establish appropriate and effective workplace relationships, have teamwork skills, and be able to share their skills and knowledge with others.

At the second level, it refers to communication between the employees and people. This means that one should be able to effectively listen to people's pain and sorrows, heal their pain psychologically, and establish an effective emotional relationship with them with effective and penetrating verbal skills. It is one of the things that should be developed and evaluated in order to provide desirable social services and increase public participation and trust.

Finally, the development of organizational competencies can result in principles of neutrality, impartiality, and independence for the society. Adaptation to the organizational culture of the Red Crescent Society, the creation of a sense of organizational belonging in them, commitment, and loyalty to the organization, and improvement of one's organizational knowledge every day are also effective strategies to improve and develop human resource competencies.

Similar to the three above-mentioned competencies, this type of competency is also influenced by several variables, namely public culture, senior management support, and laws. However, if the attitude of people towards the Red Crescent society is not positive, none of these activities will be helpful. Furthermore, the 
governing laws can sometimes encourage or prevent such activities. Perhaps the most important intervening variable is senior management support, which can act as a driving force for human resource activities.

The consequences of employing appropriate strategies influence the development of key human resource competencies and their continuous and effective evaluation. In this study, the categories of human resource efficiency, provision of desirable social services, improvement of community health, improvement of human values, increase of public trust and participation, and improvement of the financial position of the organization are the consequences of employing appropriate strategies for the evaluation and development of key human resource competencies. Based on the results, the following are suggested for the development of the key competencies of human resources in the Iranian Red Crescent society.

- The Red Crescent Society should consider the process of identification, attraction, and review of the employees' talents and plan its policies and activities accordingly.

- It is suggested that the Red Crescent Society provide a center for evaluation and gather competent evaluators in the organization in order to lay the groundwork for the investigation of the competencies of the employees and determination of their strengths and weaknesses. Therefore, the organization will be able to enhance the performance of employees by improving the competencies in which they are weak and optimizing their strengths.

- The organizational culture in the Red Crescent Society should be developed in such a way that provides the groundwork for meritocracy as well as the promotion, development, and evaluation of competencies in the organization.

- In addition to upgrading individual and organizational skills and competencies, the management of the Red Crescent Society should also consider the communicational and social competencies. The Red Crescent Society is a relief organization that should always use the help of individuals and other organizations to help people as much as possible and if it does not have an acceptable level of communicational and social competency, it will not be able to be as effective as possible.

\section{Acknowledgments}

The authors would like to express their gratitude to Dr. Soltani, the Deputy of Education, Research, and Technology, Dr. Palesh, the Research General Manager, Mr. Sodagar, the General Manager of Human Resources Development and Administrative Transformation, and other colleagues of the Iranian Red Crescent Society who supported and contributed to this research project.

\section{Conflict of Interests}

There is no conflict of interest regarding the publication of this study.

\section{References}

1. Iyewa VI, Gberevbie DE. Staff training and organizational goals attainment: a study of Airtel Nigeria Networks. Covenant Univ J Polit Int Affairs 2017; 5(1): 89-112.

2. Padmasiri MD. The relationship between training and development and employee performance of executive level employees in apparel organizations. Int Invent Sci J 2018; 2(01): 12-7.

3. Lussier RN, Hendon JR. Human resource management: functions, applications, and skill development. California: Sage Publications; 2017.

4. Campion MA, Fink AA, Ruggeberg BJ, Carr L, Phillips GM, Odman RB. Doing competencies well: best practices in competency modeling. Person Psychol 2011; 64(1): 225-62.

5. Bohlouli M, Ansari F, Kakarontzas G, Angelis L. An adaptive model for competences assessment of IT professionals. Integrated systems: innovations and applications. Berlin, Germany: Springer; 2015. P. 91-110.

6. Palšaitis R, Čižiūnienè K, Vaičiūtè K. Improvement of warehouse operations management by considering competencies of human resources. Procedia Engineering 2017; 187: 604-13.

7. Ahmadi SA, Darvish H, Sobhanifar MJ, Fazeli Kebria H. Designing, and explaining conceptual model of human resources competencies in Nahj alBalagha by utilizing content analysis method and ISM. Basij Strategic Stud Quart 2015; 17(64): 27. [In Persian].

8. Dullayaphut P, Untachai S. Development the measurement of human resource competency in SMEs in upper northeastern region of Thailand. Proc Soc Behav Sci 2013; 88: 61-72.

9. Khorasani A, Fathi Vajargah K, Zahedi H. Designing a business management competency model for Iranian industrial and manufacturing organizations. Int J Soc Sci Manag 2014; 1(1): 113. [In Persian]. 
10. Hajikarimi A, Rezaeian A, Hadizadeh A, Bonyadi NA. Designing the competencies model of human resource managers in the public sector of Iran. J Public Administ Perspect 2012; 2(8): 23-43. [In Persian].
11. Narenji Sani F, Rouhani S, Sharifi Sedeh M, Jamaledini SH. Developing the strategies of educational management in Iranian Red Crescent. J Train Dev Hum Res 2017; 4(14): 97-114. [In Persian]. 